\title{
Immune Checkpoint Inhibitors: A Promising Choice for Endometrial Cancer Patients?
}

\author{
Lucia Musacchio ${ }^{1}$, Serena Maria Boccia ${ }^{1}$, Giuseppe Caruso ${ }^{1}$ * $*$ CD , Giusi Santangelo ${ }^{1}$ (D), \\ Margherita Fischetti ${ }^{1}$, Federica Tomao ${ }^{1}$, Giorgia Perniola ${ }^{1}$, Innocenza Palaia ${ }^{1}{ }^{1}$, \\ Ludovico Muzii ${ }^{1}{ }^{(D}$, Sandro Pignata ${ }^{2}$, Pierluigi Benedetti Panici ${ }^{1}$ and Violante Di Donato ${ }^{1}$ (D) \\ 1 Department of Maternal and Child Health and Urological Sciences, University of Rome "Sapienza", \\ Policlinico “Umberto I”, 00161 Rome, Italy; lucia.musacchio@uniroma1.it (L.M.); \\ serenamaria.boccia@uniroma1.it (S.M.B.); giusi.santangelo@uniroma1.it (G.S.); \\ margherita.fischetti@uniroma1.it (M.F.); federica.tomao@uniroma1.it (F.T.); \\ giorgia.perniola@uniroma1.it (G.P.); innocenza.palaia@uniroma1.it (I.P.); ludovico.muzii@uniroma1.it (L.M.); \\ pierluigi.benedettipanici@uniroma1.it (P.B.P.); violante.didonato@uniroma1.it (V.D.D.) \\ 2 Department of Urology and Gynecology, Istituto Nazionale Tumori IRCCS “Fondazione G. Pascale”, \\ 80131 Naples, Italy; s.pignata@istitutotumori.na.it \\ * Correspondence: g.caruso@uniroma1.it; Tel.: +39-0649972535
}

Received: 30 April 2020; Accepted: 29 May 2020; Published: 3 June 2020

\begin{abstract}
Although around $80 \%$ of endometrial cancers are diagnosed at early stages and present with a 5-year survival rate exceeding $95 \%$, patients with advanced and recurrent disease show a poor prognosis and low response rates to standard chemotherapy. In the era of targeted therapy, the great advances in the understanding of programmed death-ligand 1 (PD-L1) upregulation in cancer cells, which is responsible for tumor immune escape, have contributed to the increasing interest in immune checkpoint inhibitors as a promising strategy for the treatment of several refractory solid malignancies, including endometrial cancer. Several clinical trials have investigated the efficacy and safety of immune checkpoint inhibitors in endometrial cancer, which already led to the approval of the anti-programmed cell death protein 1 (anti-PD-1) antibody pembrolizumab as a satisfactory alternative for selected patients with unresectable or metastatic disease. As the future of cancer treatment will probably rely on combination therapy strategies, currently, innovative ongoing trials are exploring the potential role of immune checkpoint inhibitors associated with chemotherapy, radiotherapy, and other targeted therapies. Moreover, further research is warranted to discover new specific biomarkers that can accurately predict the response to immunotherapy.
\end{abstract}

Keywords: endometrial cancer; immune checkpoint inhibitors; targeted therapy

\section{Introduction}

Endometrial cancer (EC) is the most common gynecological cancer in developed countries, with a lifetime risk of $2.8 \%$ [1]. The American Cancer Society estimates that, in 2020, about 65,620 new cases will be diagnosed in the United States and around 12,590 women will die from uterine cancers [2]. Around $80 \%$ of EC are diagnosed when the disease is limited to the uterus, with a five-year survival rate of over $95 \%$ [3]. However, the prognosis is significantly worse in the cases of regional spread or distant disease (68\% and 17\%, respectively) [4]. According to international guidelines, treatment for patients with early stage EC is based on surgery alone or in combination with pelvic radiation therapy, whereas patients with advanced disease are candidates for systemic chemotherapy, with carboplatin-paclitaxel doublet representing the most effective scheme [5]. Patients with metastatic or recurrent disease have a poor prognosis as they exhibit low response rates to cytotoxic chemotherapy; 
thus, it is necessary to explore new therapeutic approaches in order to provide them with the best care. In this review, we discuss the scientific rationale behind the use of immune checkpoint inhibitors in advanced and recurrent EC, exploring both published and ongoing clinical trials.

\section{Background}

The human immune system consists of two main complementary subsystems: (1) the innate immune system, which gathers dendritic cells, natural killer (NK) cells, macrophages, neutrophils, eosinophils, basophils, and mast cells and does not depend on a prior stimulation by antigens [6], and (2) the adaptive immune system, which includes B lymphocytes, cluster of differentiation 4 (CD4+) helper $\mathrm{T}$ lymphocytes, and cluster of differentiation 8 (CD8+) cytotoxic $\mathrm{T}$ lymphocytes and requires a prior antigen exposure mediated by antigen-presenting cells (APCs) for its activation [7]. Immune cells can recognize and eliminate cancer cells through the identification of tumor-specific antigens (TSA) and tumor-associated antigens (TAA) [6]. Specifically, T cells can recognize TAA and TSA peptide small fragments displayed on the surface of antigen-presenting cells (APCs) after being loaded on major histocompatibility complex (MHC) class I and II molecules [8]. Physiologically, the immune system needs to be finely regulated in order to act against pathogens without affecting self-tissues (self-tolerance). Generally, the immune response activation is elicited if two positive signals are present: the first one arises from the interaction between MHC molecules and T-cell receptors (TCR), while the second one imposes that the co-stimulatory receptor cluster of differentiation 28 (CD28), expressed on T cells surface, binds its ligand B7 on APCs [9]. In order to avoid an autoimmune reaction, there are two main inhibitory pathways: the first one depends on the cytotoxic $T$ lymphocyte antigen-4 (CTLA-4), which acts as a competitive inhibitor for the ligand B7 and is mostly expressed within secondary lymphoid organs [10]; the second one is related to the interaction between PD-1 receptor on T cells and PD-L1/2 on the tumor cells surface, and it occurs more frequently within peripheral tumor microenvironment (TME) [11,12]. The PD-1 pathway is an immune checkpoint involved in the regulation of $\mathrm{T}$ cell differentiation and apoptosis [13]. PD-1 is a protein receptor expressed by multiple immune cells, including T cells, B cells, NK cells, dendritic cells, and monocytes [14]. The interaction between PD-1 and its ligands, PD-L1 and PD-L2, inhibits cytotoxic T cell activation and differentiation [15]. Particularly, PD-L1 has been shown to be the most important ligand and is upregulated in cancer cells in order to escape the immune surveillance [16]. Indeed, antibodies targeting PD-1 and PD-L1 can block tumor-generated immunosuppression, thus preserving the immune response against cancer [17]. In light of these observations, immune checkpoint inhibitors appeared as a promising choice for the treatment of different solid and refractory malignancies, and in recent years, several studies have been conducted to assess the potential role of specific biomarkers in predicting the response to immunotherapy.

Historically, EC has been classified according to Bokhman's model into two subtypes, based on clinicopathological and molecular features. The type I EC is the most common (60-70\% of cases) and includes grades 1-2 endometrioid histology. It is associated with a high expression of estrogen receptors (ERs) and progesterone receptors (PgRs) and a good prognosis (median 5-year survival rates of 85.6\%). On the other hand, the type II represents about $30-40 \%$ of all EC, typically embracing serous, clear cell or grade 3 endometrioid histology, and is estrogen-independent [18]. It is typically more aggressive than type I and is associated with a poor prognosis, even when diagnosed at early stages $[19,20]$.

In 2013, the Cancer Genome Atlas Research Network, given the new advances on the understanding of EC genomic landscape, introduced a new molecular classification that could change adjuvant treatment for women with an aggressive disease, based on four categories: polymerase $\varepsilon$ (POLE)-ultramutated, microsatellite instability-high (MSI-H), copy-number low, and copy-number high [21]. Each of these molecular subclasses present a distinct profile of tumor aggressiveness and thus a different prognosis. The multicenter, randomized phase III trial PORTEC-4a (NCT03469674) is investigating the impact of molecular risk factors in assigning adjuvant treatment for women with stages I-II high-intermediate risk endometrial cancer. POLE-ultramutated and MSI/Mismatch Repair 
Deficiency (MMRd) tumors are associated with a better prognosis compared to the other subgroups. Specifically, POLE-ultramutated tumors show a better progression free survival (PFS) when compared to other tumors with the same histotype, grade, and stage [22-24]. Several authors have reported that MSI-H/MMRd colorectal cancers are significantly associated with a better prognosis following conventional chemotherapy $[25,26]$ and immunotherapy treatment [27]. Indeed, POLE-ultramutated and MSI-H molecular subclasses are characterized by high CD3+/CD8+ tumor-infiltrating lymphocytes and an overexpression of PD-1 and PD-L1 [28-32]. Specifically, mutations that occur in the domain of the POLE gene cause a specific phenotype characterized by a high mutational load, with increased neoantigen expression and an important activation of the patient's immune system [33,34]. Similarly, MSI-H/MMRd cancers are characterized by extremely high numbers of somatic mutations, and several studies have evaluated the relationship between MMR status and the expression of PD-1 and PD-L1 in solid tumors including EC $[35,36]$. Interestingly, Yamashita et al. reported higher cytotoxic T cells (CD8+) infiltration and PD-1/PD-L1 expression in the MMR-deficient (MMRd) group compared to the MMR-proficient (MMRp) among 149 endometrial cancer patients [37]. The high immunogenicity of these tumors explains the strong rationale behind the use of immunotherapy in these subgroups of cancers. In light of these observations, EC can represent an ideal target for immune checkpoint inhibitors and the use of MMRd/MSI status could be a predictor of the response to PD- 1 blockade in endometrial cancer.

\section{Clinical Evidence}

Several clinical trials have been published regarding the role of immune checkpoint inhibitors in endometrial cancer (Table 1).

\subsection{Anti-PD-1: Pembrolizumab}

In 2015, Le et al. first evaluated the clinical activity of pembrolizumab, an anti-PD-1 immune checkpoint inhibitor, in 41 patients presenting with progressive metastatic colorectal cancer (CRC) with or without MMR deficiency or other MMRd cancers. Pembrolizumab was administered intravenously (IV) at a dose of $10 \mathrm{mg} / \mathrm{kg}$ every 14 days in three different cohorts of patients, which included, respectively, MMRd CRC, MMRp CRC, and MMRd noncolorectal cancers, among which there were also 2 cases of EC. Co-primary endpoints were the immune-related objective response rate (ORR) and the 20-week immune-related progression-free survival (PFS). In the MMRd CRC group, the estimated ORR and the 20-week PFS were $40 \%$ and $78 \%$, respectively, versus $0 \%$ and $11 \%$ reported for MMRp CRC patients. In the MMRd cohort including two EC patients, the ORR and PFS were $71 \%$ and $67 \%$, respectively [38].

In 2016, Mehnert et al. published the case of a single patient with a rapid and persistent (more than 14 months) clinical response to anti-PD-1 pembrolizumab treatment. The molecular analysis of a pretreatment biopsy revealed a POLE-ultramutated EC, thus suggesting that the identification of a POLE mutation might have a predictive value of treatment response to pembrolizumab. However, these data need to be further investigated to be confirmed [39].

In 2017, Ott et al. published the results of the phase Ib KEYNOTE-028 trial, which enrolled 24 advanced EC patients treated with pembrolizumab $10 \mathrm{mg} / \mathrm{kg}$ IV administered every 2 weeks for a maximum of 24 months or until confirmed disease progression, intolerable toxicity, or death. The ORR reported was 13\%. Three women showed a partial response, and among them, one had POLE mutations, whereas three patients achieved a stable disease. Six-month PFS and OS were $19.0 \%$ and $68.8 \%$, respectively. Thirteen patients (54.2\%) experienced treatment-related adverse events (TRAEs), such as fatigue $(20.8 \%)$, pruritus $(16.7 \%)$, pyrexia $(12.5 \%)$, and decreased appetite $(12.5 \%)$. Grade 3 adverse events (AEs) were reported in 4 patients, including asthenia, back pain, anemia, hyperglycemia, hyponatremia, pyrexia, and diarrhea. No patient experienced grade 4 AEs or any grade immune-mediated AEs, discontinued treatment because of an $\mathrm{AE}$, or experienced treatment-related death. [40]. 
Table 1. Clinical evidence on immune checkpoint inhibitors in endometrial cancer.

\begin{tabular}{|c|c|c|c|c|}
\hline Authors, Years & Phase & Patient Population & Treatment & Findings \\
\hline Le et al., 2015 & II & 41 pts with metastatic cancer with or without MMRd, including EC & Pembrolizumab $10 \mathrm{mg} / \mathrm{kg}$ IV every 14 days & $\begin{array}{c}\text { MMRd CRC } \\
\text { ORR: } 40 \% \\
\text { PFS12: } 78 \% \\
\text { MMRp CRC } \\
\text { ORR: } 0 \% \\
\text { PFS12: } 11 \% \\
\text { MMRd non-CRC } \\
\text { ORR: } 71 \% \\
\text { PFS12: } 67 \%\end{array}$ \\
\hline Ott et al., 2017 & $\mathrm{Ib}$ & 24 pts with PD-L1 positive locally advanced or metastatic EC & Pembrolizumab $10 \mathrm{mg} / \mathrm{kg}$ IV every 2 weeks up to 24 months & $\begin{array}{l}\text { ORR: } 13 \% \\
\text { PFS: } 1.8 \text { months }\end{array}$ \\
\hline Fleming et al., 2017 & Ia & 15 pts with advanced or recurrent EC & Atezolizumab $1200 \mathrm{mg}$ or $15 \mathrm{mg} / \mathrm{kg}$ IV every 3 weeks & $\begin{array}{c}\text { ORR: } 13 \% \\
\text { PFS: } 1.7 \text { months } \\
\text { OS: } 9.6 \text { months }\end{array}$ \\
\hline Makker et al., 2019 & II & 108 pts with advanced or recurrent EC & $\begin{array}{l}\text { Pembrolizumab } 200 \mathrm{mg} \text { IV every } 3 \text { weeks plus Lenvatinib } \\
20 \mathrm{mg} \text { orally daily }\end{array}$ & $\begin{array}{l}\text { ORR (24 weeks): } 38.0 \% \\
\text { DOR: } 21.2 \text { months } \\
\text { PFS: } 7.4 \text { months } \\
\text { OS: } 16.7 \text { months } \\
\end{array}$ \\
\hline Kostantinopoulos, 2019 & II & 33 pts with MMRd/MMRp recurrent or persistent EC & Avelumab $10 \mathrm{mg} / \mathrm{kg}$ IV every 2 weeks & $\begin{array}{c}\text { MMRd cohort } \\
\text { ORR: } 26.7 \% \\
\text { PFS6: } 40 \% \\
{ }^{*} \text { MMRp cohort was closed at } \\
\text { the first stage because of } \\
\text { futility }\end{array}$ \\
\hline $\begin{array}{l}\text { Marabelle et al., } 2020 \\
\quad \text { (Keynote-158) }\end{array}$ & II & 233 pts with MSI/MMRd advanced non-CRC & Pembrolizumab $200 \mathrm{mg}$ IV every 3 weeks & $\begin{array}{l}\text { ORR: } 34.3 \% \\
\text { PFS: } 4.1 \text { months } \\
\text { OS: } 23.5 \text { months }\end{array}$ \\
\hline $\begin{array}{c}\text { Antill, } 2017 \\
\text { (PHAEDRA study) }\end{array}$ & II & 71 pts with advanced or unresectable MMRd/MMRp EC & $\begin{array}{c}\text { Durvalumab } 1500 \mathrm{mg} \text { IV every } 28 \text { days until disease } \\
\text { progression or prohibitive toxicity }\end{array}$ & $\begin{array}{l}\text { MMRd } \\
\text { OTR: } 40 \% \\
\text { MMRp } \\
\text { OTR: } 3 \%\end{array}$ \\
\hline $\begin{array}{l}\text { Oaknin, } 2019 \\
\text { (GARNET study) }\end{array}$ & II & 110 pts with recurrent or advanced MSI/MSS EC & Dostarlimab 500 mg IV every 3 weeks & $\begin{array}{l}\text { MSI cohort } \\
\text { ORR: } 50 \% \\
\text { MSS cohort } \\
\text { ORR: } 19.1\end{array}$ \\
\hline
\end{tabular}

Abbreviations: ORR, overall response rate; OS, overall survival; PFS, progression-free survival; PFS12, progression-free survival at 12 months; PFS6, progression-free survival at 6 months; OTR, objective tumor response; DOR, duration of response; MMRd, mismatch repair deficient; MMRp, mismatch repair proficient; EC, endometrial cancer; MSI, microsatellite instability; MSS, microsatellite stability; IV, intravenous; pts, patients; CRC, colorectal cancer. 
In a recent phase II trial, Makker et al. tested the anti-PD-1 pembrolizumab at a dosage of $200 \mathrm{mg}$ IV every 3 weeks in combination with lenvatinib, a multikinase-inhibitor of vascular endothelial growth factor (VEGFR), at a dosage of $20 \mathrm{mg}$ daily orally in 108 advanced recurrent EC patients. The primary endpoint was the ORR at 24 weeks, according to the response evaluation criteria in solid tumors (RECIST) criteria 1.1. Forty-two (38.0\%) patients had an objective response to lenvatinib plus pembrolizumab. The median PFS and overall survival (OS) were 7.4 months and 16.7 months, respectively. For patients with MSS/MMRp tumors, the ORR was $37.2 \%$, whereas for patients with MSI-H/MMRd tumors, the ORR was $63.6 \%$. The median duration of response (DOR) was not estimable (NE) (95\% CI, 7.4 months to NE) for patients with MSS/MMRp tumors and was 21.2 months (95\% CI, 7.3 months to NE) for patients with MSI-H/MMRd tumors. The most frequently reported any-grade AEs were hypertension $(66(61 \%))$, fatigue $(56(51.9 \%))$, diarrhea $(57(52.8 \%))$, and hypothyroidism (48 (44.4\%)). Grade 3-4 AEs occurred in $75(69.4 \%)$ patients [41].

Results from the Keynote-158 study demonstrated the clinical benefit of pembrolizumab for previously treated unresectable or metastatic MSI-H/MMRd noncolorectal cancer patients. Among 233 patients enrolled, 47 were EC patients. Eligible participants received pembrolizumab $200 \mathrm{mg}$ IV every 21 days for 35 cycles or until documented disease progression, unacceptable toxicity, or patient/investigator decision. The primary endpoint was ORR, defined as the proportion of patients with confirmed complete/partial response per RECIST 1.1. An ORR of 57.1\% was reported for EC patients, with a median PFS of 25.7 months. One hundred and fifty-one of 233 patients $(64.8 \%)$ experienced TRAEs, and among them, $34(14.6 \%)$ had grade $3-5$ AEs. The most common toxicities were fatigue $(14.6 \%)$, pruritus $(12.9 \%)$, diarrhea $(12.0 \%)$, and asthenia $(10.7 \%$ ). Most frequent grade 3 AEs were increased gamma-glutamyltransferase $(1.7 \%)$ and pneumonitis $(1.3 \%)$. Three patients had grade 4 AEs: one patient had Guillain-Barre syndrome (a patient with gastric cancer), one had increased alanine aminotransferase (ALT), and another one had decreased neutrophil count and enterocolitis [42].

\subsection{Anti-PD-1: Nivolumab}

In 2016, Santin et al. reported two cases of recurrent/metastatic EC, respectively a mixed clear cell and endometrioid (CC/EAC) POLE-ultramutated EC and a serous MSH6-mutated EC, not responding to surgery, chemotherapy, and radiotherapy and treated with nivolumab, a novel anti-PD-1 antibody, administered IV at a dosage of $3 \mathrm{mg} / \mathrm{kg}$ once biweekly. Both tumor samples evaluated in the pretreatment setting showed moderate peri- and intratumoral lymphocytic infiltrate (especially CD8 T cells) and moderate PD-1 and PD-L1 expression. Patients showed a persistent clinical response to nivolumab without severe toxicities, as confirmed by a computed tomography (CT) scan performed, respectively, at 7 and 9 months from the beginning of treatment [43].

\subsection{Anti-PD-1: Dostarlimab}

Preliminary data from the GARNET study were presented at the 2019 Society for Gynecologic Oncology (SGO) annual meeting on women's cancer. One hundred and ten EC patients received dostarlimab 500 mg every 3 weeks. The ORR was $27.7 \%$ (50\% in MSI-H and 19.1\% in MSS). Sixty-eight EC patients (68\%) experimented at least one TRAE. Grade $\geq 3$ AEs were reported in 13 patients $(11.8 \%)$, and the most common was increased serum levels of aspartate aminotransferase [44].

\subsection{Anti-PD-L1: Atezolizumab}

Fleming et al. presented the results of a phase Ia clinical trial in which atezolizumab, an anti-PD-L1 antibody, was tested in 15 women with advanced and recurrent EC with microsatellite stability (MSS), MSI-H, or microsatellite unknown status. Patients received atezolizumab $1200 \mathrm{mg}$ or $15 \mathrm{mg} / \mathrm{mq}$ IV in monotherapy every 21 days. Two women showed a partial response, while another two achieved a stable disease with an ORR of $13 \%$ and a disease control rate (DCR) of $27 \%$. Both responders had a PD-L1 expression above 5\% and presented, respectively, MSS and MSI-H status. It was reported 
a median PFS of 1.7 months and a median OS of 9.6 months. Only two patients experienced severe drug-related AEs (colitis and rash), whereas no G4-5 adverse events were recorded [45].

\subsection{Anti-PD-L1: Avelumab}

Konstantinopoulos et al. published the results of a phase II trial, in which avelumab was tested in patients with MMRd/MMRp-recurrent or -persistent endometrial cancer. Thirty-three patients were enrolled. Avelumab was administered at $10 \mathrm{mg} / \mathrm{kg}$ IV every 2 weeks until progression or unacceptable toxicity. No patient with POLE-ultramutated tumor was enrolled in MMRd and MMRp cohorts. Co-primary endpoints were PFS at 6 months (PFS6) and ORR according to RECIST criteria 1.1. The MMRp cohort was closed at the first stage because only one out of 16 patients exhibited both ORR and PFS6 responses. The MMRd cohort achieved the primary endpoint of four objective responses after the accrual of only 17 patients. Of 15 patients who received avelumab, four exhibited an objective response ( 1 complete response and 3 partial responses; ORR, $26.7 \%$; $95 \%$ CI, $7.8 \%$ to $55.1 \%$ ) and 6 (including all four objective responses) PFS6 responses (PFS6, 40.0\%; 95\% CI, 16.3\% to 66.7\%). Responses were observed in the absence of PD-L1 expression. Twenty-two patients experienced TRAEs. Particularly, 6 patients reported grade 3 toxicity, including anemia, sinus bradycardia, hypothyroidism, diarrhea, myositis, and rash acneiform [46].

\subsection{Anti-PD-L1: Durvalumab}

Data from the PHAEDRA study was presented at the American Society of Clinical Oncology (ASCO) 2019 and showed the activity of durvalumab as a single agent in MMRd and MMRp cohorts. Seventy-one patients with advanced EC were enrolled: 35 patients with MMRp progressing after 1-3 lines of chemotherapy and 36 patients with MMRd progressing after 0-3 lines of chemotherapy. All patients received durvalumab at dosage of $1500 \mathrm{mg}$ IV every 4 weeks. Among MMRd patients, the ORR was $40 \%$ (4 complete responses and 10 partial responses), whereas within the MMRp group, the ORR was 3\% (one partial response). Adverse events occurred in 14 patients, including hyperthyroidism, hypothyroidism, pneumonitis, and hepatitis [47].

\section{Main Ongoing Trials}

Immune checkpoint inhibitors are under evaluation in several phase I, II, and III clinical trials, alone or in combination with other drugs (Table 2). NCT03572478 is a phase Ib/IIa study on the combination of nivolumab with the poly (ADP-ribose) polymerase (PARP) inhibitor rucaparib in metastatic or recurrent $\mathrm{EC}$ patients. In phase $\mathrm{Ib}$, patients will receive rucaparib plus nivolumab in 4-week cycles, while in phase IIa, patients will be randomized to receive nivolumab alone, rucaparib alone, or rucaparib in combination with nivolumab. The primary endpoint is to evaluate the dose-limiting toxicities (DLT) rate for the combination of rucaparib and nivolumab [48]. Nivolumab is also being studied in a phase II clinical trial (NCT02982486) in association with ipilimumab in patients with nonresectable/metastatic MMRd EC. Patients will receive nivolumab $240 \mathrm{mg}$ IV every 2 weeks plus ipilimumab $1 \mathrm{mg} / \mathrm{mq}$ IV every 6 weeks. The primary endpoint is ORR according to RECIST 1.1 [49]. NCT03241745 is a single-center, non-randomized, open-label, phase II study with the aim to assess the safety of nivolumab in patients with MSI/MMRd hypermutated uterine cancers, including endometrial carcinoma. Patients will receive nivolumab $480 \mathrm{mg}$ IV once every 4 weeks until disease progression or unacceptable toxicity. The primary endpoint is PFS [50].

Moreover, pembrolizumab is being investigated in phase I, II, and III clinical trials. NCT02549209 is a single-arm, open-label, multi-center phase II study in patients with newly diagnosed stage III/IV or recurrent EC that aims to assess the association of pembrolizumab with carboplatin/paclitaxel therapy. Patients with no prior therapy will receive pembrolizumab $200 \mathrm{mg}$ plus carboplatin AUC 6 and paclitaxel $175 \mathrm{mg} / \mathrm{mq}$ every 21 days, whereas those with prior external beam radiation therapy (EBRT) and/or platinum-based chemotherapy must initiate paclitaxel and carboplatin at a reduced dose (paclitaxel $135 \mathrm{mg} / \mathrm{mq}$ plus carboplatin AUC 5). The primary endpoint is the ORR [51]. 
Table 2. Ongoing clinical trials on immune checkpoint inhibitors in endometrial cancer.

\begin{tabular}{|c|c|c|c|c|c|c|}
\hline DRUGS & Description/Condition & Setting & Primary Endpoint & Phase & Status & Trial Identifier \\
\hline Nivolumab & $\begin{array}{l}\text { A Phase Ib/IIa Study of Rucaparib (PARP Inhibitor) } \\
\text { Combined with Nivolumab in Metastatic } \\
\text { Castrate-Resistant Prostate Cancer and } \\
\text { Advanced/Recurrent Endometrial Cancer }\end{array}$ & Advanced/Recurrent EC & DLT & $\mathrm{I} / \mathrm{II}$ & Recruiting & NCT03572478 \\
\hline Nivolumab & $\begin{array}{c}\text { A Phase II Trial of IDO-Inhibitor, BMS-986205, and PD-1 } \\
\text { Inhibitor, Nivolumab, in Patients with Recurrent or } \\
\text { Persistent Endometrial Cancer or Endometrial } \\
\text { Carcinosarcomas (CA017-056) }\end{array}$ & Recurrent/Persistent EC & ORR & II & Recruiting & NCT04106414 \\
\hline $\begin{array}{l}\text { Nivolumab + } \\
\text { Ipilimumab }\end{array}$ & $\begin{array}{c}\text { A Phase II Single Arm Study Assessing Efficacy and Safety } \\
\text { of Nivolumab Plus Ipilimumab in Nonresectable/Metastatic } \\
\text { Sarcoma and Endometrial Carcinoma Patients with } \\
\text { Somatic Deficient MMR as a Selection Tool }\end{array}$ & EC with Somatic MMRd & ORR & II & Not yet Recruiting & NCT02982486 \\
\hline Nivolumab & $\begin{array}{l}\text { Phase II Trial of Single-Agent Nivolumab in Patients with } \\
\text { Microsatellite Unstable/Mismatch Repair } \\
\text { Deficient/Hypermutated Uterine Cancer }\end{array}$ & Metastatic/Recurrent EC & PFS & II & Recruiting & NCT03241745 \\
\hline $\begin{array}{l}\text { Nivolumab } \\
\quad+/- \\
\text { Ipilimumab }\end{array}$ & $\begin{array}{l}\text { Phase Ib Clinical Investigation of Intraperitoneal } \\
\text { Ipilimumab and Nivolumab in Patients with Peritoneal } \\
\text { Carcinomatosis Due to Gynecologic Cancers }\end{array}$ & Recurrent EC & MTD & I & Recruiting & NCT03508570 \\
\hline Nivolumab & $\begin{array}{l}\text { A Phase 1a/1b Study of COM701 as Monotherapy and in } \\
\text { Combination with an Anti-PD-1 Antibody in Subjects with } \\
\text { Advanced Solid Tumors }\end{array}$ & $\begin{array}{l}\text { Advanced or Metastatic } \\
\text { Solid Tumor included EC }\end{array}$ & MTD, DLT, AE & I & Recruiting & NCT03667716 \\
\hline Nivolumab & $\begin{array}{l}\text { Targeted Therapy Directed by Genetic Testing in Treating } \\
\text { Patients with Advanced Refractory Solid Tumors, } \\
\text { Lymphomas, or Multiple Myeloma (The MATCH } \\
\text { Screening Trial) }\end{array}$ & $\begin{array}{l}\text { Advanced or Metastatic } \\
\text { Solid Tumor included EC }\end{array}$ & ORR & II & Recruiting & NCT02465060 \\
\hline Pembrolizumab & $\begin{array}{c}\text { A Phase 2, Two-Stage Study of Mirvetuximab Soravtansine } \\
\text { (IMGN853) in Combination with Pembrolizumab in } \\
\text { Patients with Microsatellite Stable (MSS) Recurrent or } \\
\text { Persistent Endometrial Cancer (EC) }\end{array}$ & Advanced/Recurrent EC & ORR, PFS & II & Recruiting & NCT03835819 \\
\hline Pembrolizumab & $\begin{array}{l}\text { A Phase II Evaluation of Pembrolizumab, a Humanized } \\
\text { Antibody Against PD-1, in the Treatment of Persistent or } \\
\text { Recurrent Hypermutated/Ultramutated Endometrial } \\
\text { Cancer Identified by Next Generation Sequencing (NGS) } \\
\text { and Comprehensive Genomic Profiling (CGP) }\end{array}$ & Persistent/Recurrent EC & ORR, AE & II & Recruiting & NCT02899793 \\
\hline Pembrolizumab & $\begin{array}{l}\text { A Phase Ib Trial of Vaginal Cuff Brachytherapy }+ \\
\text { Pembrolizumab (MK3475) Followed by } 3 \text { Cycles of Dose } \\
\text { Dense Paclitaxel/q } 21 \text { Day Carboplatin + Pembrolizumab } \\
\text { (MK3475) in High Intermediate Risk Endometrial Cancer }\end{array}$ & High/Intermediate Risk EC & $\begin{array}{l}\text { Proportion of } \\
\text { patients completing } \\
\text { three cycles }\end{array}$ & I & Not yet Recruiting & NCT03932409 \\
\hline
\end{tabular}


Table 2. Cont.

\begin{tabular}{|c|c|c|c|c|c|c|}
\hline DRUGS & Description/Condition & Setting & Primary Endpoint & Phase & Status & Trial Identifier \\
\hline Pembrolizumab & $\begin{array}{l}\text { Pembrolizumab with Axitinib in Recurrent Endometrial } \\
\text { Cancer with Deficient Mismatch Repair System Post PD1 } \\
\text { Exposure: Phase II Trial }\end{array}$ & Recurrent EC with MMRd & ORR & II & Not yet recruiting & NCT04197219 \\
\hline Pembrolizumab & $\begin{array}{c}\text { Phase II Study of Pembrolizumab in Combination with } \\
\text { Carboplatin and Paclitaxel for Advanced or Recurrent } \\
\text { Endometrial Adenocarcinoma }\end{array}$ & Advanced or Recurrent EC & ORR & II & Recruiting & NCT02549209 \\
\hline Pembrolizumab & $\begin{array}{l}\text { Study of Pembrolizumab Combined with Ataluren in } \\
\text { Patients with Metastatic pMMR and dMMR Colorectal } \\
\text { Adenocarcinomas or Metastatic dMMR Endometrial } \\
\text { Carcinoma: the ATAPEMBRO Study }\end{array}$ & Metastatic EC MMRd & $\mathrm{AE}$ & $\mathrm{I} / \mathrm{II}$ & Recruiting & NCT04014530 \\
\hline Pembrolizumab & $\begin{array}{l}\text { Immunotherapy with MK-3475 in Surgically Resectable } \\
\text { Endometrial Carcinoma }\end{array}$ & Advanced EC & $\mathrm{AE}$ & I & $\begin{array}{l}\text { Active, not } \\
\text { recruiting }\end{array}$ & NCT02630823 \\
\hline Pembrolizumab & $\begin{array}{c}\text { Phase II Trial of Pembrolizumab in Combination with } \\
\text { Doxorubicin in Advanced, Recurrent or Metastatic } \\
\text { Endometrial Cancer (TOPIC) }\end{array}$ & Advanced or Metastatic EC & PFS & II & $\begin{array}{l}\text { Active, not } \\
\text { recruiting }\end{array}$ & NCT03276013 \\
\hline Pembrolizumab & $\begin{array}{c}\text { A Multicenter, Open-label, Randomized, Phase } 3 \text { Trial to } \\
\text { Compare the Efficacy and Safety of Lenvatinib in } \\
\text { Combination with Pembrolizumab Versus Treatment of } \\
\text { Physician's Choice in Participants with Advanced } \\
\text { Endometrial Cancer }\end{array}$ & Advanced EC & PFS, OS & III & $\begin{array}{l}\text { Active, not } \\
\text { recruiting }\end{array}$ & NCT03517449 \\
\hline Pembrolizumab & $\begin{array}{l}\text { A Phase III Randomized, Placebo-Controlled Study of } \\
\text { Pembrolizumab (MK-3475, NSC \#776864) in Addition to } \\
\text { Paclitaxel and Carboplatin for Measurable Stage III or IVA, } \\
\text { Stage IVB, or Recurrent Endometrial Cancer }\end{array}$ & Advanced or Recurrent EC & PFS & III & Recruiting & NCT03914612 \\
\hline Pembrolizumab & $\begin{array}{c}\text { A Phase III Randomized Trial of Radiation +/- MK-3475 } \\
\text { (Pembrolizumab) for Newly Diagnosed, High Intermediate } \\
\text { Risk Mismatch Repair Deficient (dMMR) Endometrioid } \\
\text { Endometrial Cancer }\end{array}$ & Early stage EC & 3 years RFS & III & Not yet recruiting & NCT04214067 \\
\hline Pembrolizumab & $\begin{array}{c}\text { A Phase } 3 \text { Randomized, Open-Label, Study of } \\
\text { Pembrolizumab (MK-3475) Plus Lenvatinib } \\
\text { (E7080/MK-7902) Versus Chemotherapy for First-Line } \\
\text { Treatment of Advanced or Recurrent Endometrial } \\
\text { Carcinoma (LEAP-001) }\end{array}$ & Advanced or Recurrent EC & PFS, OS & III & Recruiting & NCT03884101 \\
\hline Pembrolizumab & $\begin{array}{l}\text { A Phase II Investigation of Pembrolizumab (Keytruda) in } \\
\text { Combination with Radiation and an Immune Modulatory } \\
\text { Cocktail in Patients with Cervical and Uterine Cancer } \\
\text { (PRIMMO Trial) }\end{array}$ & Advanced or Refractory EC & ORR & II & Recruiting & NCT03192059 \\
\hline Pembrolizumab & $\begin{array}{c}\text { A Pilot Study Investigating the Effect of Pembrolizumab on } \\
\text { the Tumoral Immunoprofile of Gynecologic Cancers of } \\
\text { Mullerian Origin }\end{array}$ & EC any stages & $\begin{array}{l}\text { Change in tumor } \\
\text { Immune Infiltrates }\end{array}$ & Early phase I & $\begin{array}{l}\text { Active, not } \\
\text { recruiting }\end{array}$ & NCT02728830 \\
\hline
\end{tabular}


Table 2. Cont.

\begin{tabular}{|c|c|c|c|c|c|c|}
\hline DRUGS & Description/Condition & Setting & Primary Endpoint & Phase & Status & Trial Identifier \\
\hline Pembrolizumab & $\begin{array}{l}\text { A Phase 1a/1b Study of FPA150, an Anti-B7-H4 Antibody, } \\
\text { in Patients with Advanced Solid Tumors }\end{array}$ & Advanced EC & MTD & Early phase I & $\begin{array}{l}\text { Active, not } \\
\text { recruiting }\end{array}$ & NCT03514121 \\
\hline Pembrolizumab & $\begin{array}{c}\text { A Platform Study Exploring the Safety, Tolerability, Effect } \\
\text { on the Tumor Microenvironment, and Efficacy of } \\
\text { Pembrolizumab + INCB Combinations in Advanced Solid } \\
\text { Tumors }\end{array}$ & Advanced or Metastatic EC & $\mathrm{AE}$ & I & $\begin{array}{l}\text { Active, not } \\
\text { recruiting }\end{array}$ & NCT02646748 \\
\hline Pembrolizumab & $\begin{array}{l}\text { A Phase 1/1b Multicenter Study to Evaluate the } \\
\text { Humanized Anti-cd73 Antibody, cpi-006, as a Single Agent } \\
\text { or in Combination with Ciforadenant, with } \\
\text { Pembrolizumab, and with Ciforadenant plus } \\
\text { Pembrolizumab in Adult Subjects with Advanced Cancers }\end{array}$ & Advanced EC & DLT, AE, MDL & I & Recruiting & NCT03454451 \\
\hline Pembrolizumab & $\begin{array}{l}\text { A Phase 1/2 Study Exploring the Safety, Tolerability, and } \\
\text { Efficacy of MK-3475 in Combination with INCB024360 in } \\
\text { Subjects with Selected Cancers (ECHO-202/KEYNOTE-037) }\end{array}$ & Advanced or Metastatic EC & $\mathrm{AE}, \mathrm{ORR}$ & $\mathrm{I} / \mathrm{II}$ & $\begin{array}{l}\text { Active, not } \\
\text { recruiting }\end{array}$ & NCT02178722 \\
\hline Pembrolizumab & $\begin{array}{c}\text { A Clinical Trial of Pembrolizumab (MK-3475) Evaluating } \\
\text { Predictive Biomarkers in Subjects with Advanced Solid } \\
\text { Tumors (KEYNOTE 158) }\end{array}$ & Advanced EC & ORR & II & Recruiting & NCT02628067 \\
\hline Pembrolizumab & $\begin{array}{l}\text { A Phase } 1 / 2 \text { Safety and Efficacy Study of INCAGN01876 in } \\
\text { Combination with Immune Therapies in Subjects with } \\
\text { Advanced or Metastatic Malignancies }\end{array}$ & Advanced or Metastatic EC & $\mathrm{AE}, \mathrm{ORR}, \mathrm{CRR}$ & $\mathrm{I} / \mathrm{II}$ & $\begin{array}{l}\text { Active, not } \\
\text { recruiting }\end{array}$ & NCT03277352 \\
\hline Pembrolizumab & $\begin{array}{l}\text { An Open-Label Phase 1b Trial of Lenvatinib Plus } \\
\text { Pembrolizumab in Subjects with Selected Solid Tumors }\end{array}$ & Refractory EC & $\mathrm{AE}, \mathrm{DLT}$ & I & $\begin{array}{l}\text { Active, not } \\
\text { recruiting }\end{array}$ & NCT03006887 \\
\hline Pembrolizumab & $\begin{array}{l}\text { A Phase 1A/B Study to Evaluate the Safety and Tolerability } \\
\text { of ETC-1922159 in Advanced Solid Tumours }\end{array}$ & $\begin{array}{l}\text { Advanced, Metastatic or } \\
\text { Refractory EC }\end{array}$ & MTD, AE & I & $\begin{array}{l}\text { Active, not } \\
\text { recruiting }\end{array}$ & NCT02521844 \\
\hline Avelumab & $\begin{array}{l}\text { A Phase 2, Two-Group, Two-Stage, Open-Label Study of } \\
\text { Avelumab (MSB0010718C) in Patients with MSS, MSI-H, } \\
\text { and POLE-mutated Recurrent or Persistent Endometrial } \\
\text { Cancer and of Avelumab (MSB0010718C)/Talazoparib } \\
\text { (MDV3800, BMN 673) in Patients with MSS Recurrent or } \\
\text { Persistent Endometrial Cancer }\end{array}$ & Recurrent or Metastatic EC & PFR6 & II & Recruiting & NCT02912572 \\
\hline Avelumab & $\begin{array}{c}\text { MITO END-3: A Randomized Phase II Trial of Carboplatin } \\
\text { + Paclitaxel Compared to Carboplatin + Paclitaxel + } \\
\text { Avelumab in Advanced (Stages III-IV) or Recurrent } \\
\text { Endometrial Cancer }\end{array}$ & Advanced or Recurrent EC & PFS & II & Not yet recruiting & NCT03503786 \\
\hline Durvalumab & $\begin{array}{c}\text { Durvalumab and Olaparib in Metastatic or Recurrent } \\
\text { Endometrial Cancer }\end{array}$ & Advanced or Metastatic EC & PFS & II & Recruiting & NCT03951415 \\
\hline Durvalumab & $\begin{array}{l}\text { A Phase } 2 \text { Trial of Durvalumab (MEDI4736) (Anti-PD-L1 } \\
\text { Antibody) with or without Tremelimumab (Anti-CTLA-4 } \\
\text { Antibody) in Patients with Persistent or Recurrent } \\
\text { Endometrial Carcinoma and Endometrial Carcinosarcoma }\end{array}$ & Recurrent or Persistent EC & ORR & II & Recruiting & NCT03015129 \\
\hline
\end{tabular}


Table 2. Cont

\begin{tabular}{|c|c|c|c|c|c|c|}
\hline DRUGS & Description/Condition & Setting & Primary Endpoint & Phase & Status & Trial Identifier \\
\hline Durvalumab & $\begin{array}{l}\text { A Randomised, Multicentre, Double-blind, } \\
\text { Placebo-controlled, Phase III Study of First-Line } \\
\text { Carboplatin and Paclitaxel in Combination with } \\
\text { Durvalumab, Followed by Maintenance Durvalumab with } \\
\text { or without Olaparib in Patients with Newly Diagnosed } \\
\text { Advanced or Recurrent Endometrial Cancer (DUO-E) }\end{array}$ & Advanced or Recurrent EC & PFS & III & Not yet recruiting & NCT04269200 \\
\hline Durvalumab & $\begin{array}{l}\text { A Phase } 1 \text { Study of Durvalumab, Tremelimumab, and } \\
\text { Radiotherapy in Recurrent Gynecologic Cancer }\end{array}$ & $\begin{array}{l}\text { Metastatic or Unresectable } \\
\text { EC }\end{array}$ & MTD & I & Recruiting & NCT03277482 \\
\hline Durvalumab & $\begin{array}{l}\text { Pilot Study of Durvalumab (MEDI4736) in Combination } \\
\text { with Vigil in Advanced Women's Cancers }\end{array}$ & Advanced EC & $\mathrm{AE}$ & II & Not yet recruiting & NCT02725489 \\
\hline Durvalumab & $\begin{array}{l}\text { Phase 1B, Open-Label, Dose Escalation, and Cohort } \\
\text { Expansions Trial of Naptumomab Estafenatox (Nap, } \\
\text { ABR-217620) in Combination with Durvalumab } \\
\text { (MEDI4736) in Subjects with Selected Advanced or } \\
\text { Metastatic Solid Tumors }\end{array}$ & Advanced EC & AE, MTD, RP2D & II & Recruiting & NCT03983954 \\
\hline Atezolizumab & $\begin{array}{c}\text { Phase III Double-blind Randomized Placebo Controlled } \\
\text { Trial of Atezolizumab in Combination with Paclitaxel and } \\
\text { Carboplatin in Women with Advanced/Recurrent } \\
\text { Endometrial Cancer }\end{array}$ & Advanced or Recurrent EC & OS, PFS & III & Recruiting & NCT03603184 \\
\hline Atezolizumab & $\begin{array}{c}\text { A Phase II, Single Arm Study of Atezolizumab + } \\
\text { Bevacizumab in Women with Advanced, Recurrent, or } \\
\text { Persistent Endometrial Cancer }\end{array}$ & Recurrent EC & OTR & II & Recruiting & NCT03526432 \\
\hline Atezolizumab & $\begin{array}{c}\text { An Open Label, Non-Randomized Multisite Phase II Trial } \\
\text { Combining Bevacizumab, Atezolizumab, and Rucaparib } \\
\text { for the Treatment of Previously Treated Recurrent and } \\
\text { Progressive Endometrial Carcinoma }\end{array}$ & Recurrent or Progressive EC & ORR & II & Recruiting & NCT03694262 \\
\hline Atezolizumab & $\begin{array}{l}\text { A Phase } 1 \mathrm{~b} \text { to Assess the Safety and Tolerability of } \\
\text { Carboplatin-Cyclophosphamide Combined with } \\
\text { Atezolizumab, an Antibody that Targets Programmed } \\
\text { Death Ligand 1 (PD-L1), in Patients with Advanced Breast } \\
\text { Cancer and Gynaecologic Cancer }\end{array}$ & Advanced EC & Toxicity & I & $\begin{array}{l}\text { Active, not } \\
\text { recruiting }\end{array}$ & NCT02914470 \\
\hline Atezolizumab & $\begin{array}{c}\text { A Phase 1b Dose-Escalation Study of Cabozantinib (XL184) } \\
\text { Administered Alone or in Combination with Atezolizumab } \\
\text { to Subjects with Locally Advanced or Metastatic } \\
\text { Solid Tumors }\end{array}$ & Advanced or Metastatic EC & MTD, ORR & I/II & Recruiting & NCT03170960 \\
\hline
\end{tabular}

Abbreviations: ORR, overall response rate; OS, overall survival; PFS, progression-free survival; PFS6 progression-free survival at 6 months; DLT, dose-limiting toxicities; MTD, maximum tolerated dose; OTR, objective tumor response; DOR, duration of response; RP2D, recommended phase 2 dose; AE, adverse event; MMRd, mismatch repair deficient; MMRp, mismatch repair proficient; EC, endometrial cancer. 
The TOPIC study (NCT03276013) is non-randomized, single-arm, multi-center, phase II study of pembrolizumab in combination with doxorubicin in patients with recurrent/metastatic EC. Patients will receive doxorubicin $60 \mathrm{mg} / \mathrm{kg}$ IV every 3 weeks for up to 9 cycles in combination with pembrolizumab (MK-3475) $200 \mathrm{mg}$ IV every 3 weeks. The primary endpoint is the PFS6 [52]. NCT03517449 (KEYNOTE-775) is a multi-center, open-label, randomized, phase III trial investigating the efficacy and safety of combined lenvatinib and pembrolizumab compared to treatment with doxorubicin or paclitaxel in patients with advanced EC. Women in the experimental arm will receive pembrolizumab $200 \mathrm{mg}$ IV on day 1 of each 21-day cycle plus lenvatinib $20 \mathrm{mg}$ orally once daily during each 21-day cycle for up to 35 cycles. Patients in the comparator arm will receive doxorubicin $60 \mathrm{mg} / \mathrm{mq} \mathrm{IV}$ on day 1 of each 21-day cycle for up to a maximum cumulative dose of $500 \mathrm{mg} / \mathrm{mq}$ or paclitaxel $80 \mathrm{mg} / \mathrm{mq}$ IV on a 28-day cycle (3 weeks of paclitaxel once a week and 1 week without paclitaxel). Co-primary endpoints are PFS and OS [53].

Two phase III clinical trials are evaluating the efficacy of pembrolizumab combined with other drugs for advanced or recurrent EC patients. In the randomized, placebo-controlled NCT03914612 study, patients will receive pembrolizumab every 21 days in association with carboplatin and paclitaxel for up to 6 cycles and then pembrolizumab every 3 weeks for up to 29 cycles as maintenance in the absence of disease progression or unacceptable toxicity [54]. The randomized, open-label NCT03884101 trial aims to compare the efficacy of pembrolizumab $200 \mathrm{mg}$ IV on day 1 of each 21-day cycle in association with lenvatinib $20 \mathrm{mg}$ orally once daily versus standard chemotherapy [55]. In both clinical trials, the primary endpoint is PFS.

MITO END-3 (NCT03503786) is a randomized, phase II clinical trial which compares carboplatin/paclitaxel to carboplatin/paclitaxel plus avelumab in advanced or recurrent EC. Patients in the experimental arm will receive carboplatin AUC 5, paclitaxel $175 \mathrm{mg} / \mathrm{mq}$, and avelumab $10 \mathrm{mg} / \mathrm{kg}$ every 21 days for 6-8 cycles plus avelumab $10 \mathrm{mg} / \mathrm{kg}$ as maintenance every 14 days until disease progression or unacceptable toxicity. The primary endpoint is PFS [56].

Furthermore, durvalumab is currently under evaluation in several clinical trials. NCT04269200 is a randomized, multicenter, double-blind, placebo-controlled, phase III study which aims to assess the efficacy and safety of durvalumab in combination with platinum-based chemotherapy (paclitaxel plus carboplatin) followed by maintenance durvalumab with or without olaparib for patients with newly diagnosed advanced or recurrent EC. In cohort A, patients will receive carboplatin/paclitaxel plus durvalumab placebo followed by maintenance durvalumab placebo and olaparib placebo; in cohort B, patients will undergo platinum-based chemotherapy and durvalumab followed by maintenance durvalumab and olaparib placebo; and in cohort $C$, they will receive platinum-based chemotherapy and durvalumab followed by maintenance durvalumab and olaparib. PFS is the primary endpoint [57].

Finally, the EndoBARR trial (NCT03694262) is an open label, non-randomized multicenter, phase II trial evaluating the efficacy and safety of combined rucaparib, atezolizumab, and bevacizumab in recurrent and progressive EC. Atezolizumab will be administered at dosage of $1200 \mathrm{mg}$ IV (every 3 weeks) together with bevacizumab $15 \mathrm{mg} / \mathrm{mq}$ (every 3 weeks) and rucaparib $600 \mathrm{mg}$ twice daily. The primary endpoint is ORR [58].

\section{Toxicities}

Understanding the spectrum of the unique toxicities associated with immune checkpoint inhibition is crucial, as they may be acute and life-threatening. The precise pathophysiology underlying immune-related AEs is unknown, although it appears related to the role that immune checkpoints play in maintaining immunologic homeostasis. As CTLA-4 and PD-1 agents act differently, their use causes different immune-related AEs. Generally, the PD-1 blockade seems to be better tolerated and has a lower AE frequency than the CTLA-4 blockade. Moreover, CTLA-4-related AEs increase with increasing dose whereas PD-1-related AEs seem not to be dose-related [59]. Overall, AEs affect over two-thirds of patients. Severe immune-related AEs occur in $10 \%$ to $20 \%$ of cases treated with CTLA-4 inhibitors, whereas their frequency is lower ( $1 \%$ to $2 \%$ ) in patients treated with PD-1 inhibitors [60]. 
Immune-related AEs usually develop within the first few weeks to months after treatment initiation, and there is currently no known predisposing risk factor. Furthermore, most studies indicate that prolonged treatment does not result in an increased incidence of immune-related AEs [61]. A current area of investigation is whether the degree of side effects is correlated with treatment response, though durable responses have been seen in the absence of severe reactions. Although any organ system can be affected, immune-related AEs most commonly involve gastrointestinal tract, endocrine glands, skin, and liver. Less often, the central nervous system and cardiovascular, pulmonary, musculoskeletal, and hematologic systems are involved [62]. The management of all potential immune-related adverse events requires a multidisciplinary approach.

\section{Conclusions and Future Perspectives}

Over the last years, immunotherapy has meaningfully changed the paradigm of care of several solid tumors and, currently, it represents an active area of research aiming to identify which types of cancer could benefit most from it. Recently, the great advances in the understanding of cancer genome have contributed to the increasing interest in immune checkpoint inhibitors as a promising alternative strategy for refractory cancers $[63,64]$. Based on the results from several clinical trials, in 2017, the Food and Drug Administration (FDA) approved pembrolizumab for patients with unresectable or metastatic MSI-H or MMRd solid tumors, including endometrial cancer. Moreover, data coming from Keynote 146 have led to the approval of the combination of pembrolizumab with lenvatinib in patients with highly pretreated, advanced non-MSI-H, or MMRd endometrial carcinoma, not amenable to surgery or radiation. Results from several clinical trials have shown that MMRd EC patients respond better to immune checkpoint inhibitors than MMR-p. However, there was no stratification of MSI-H EC tumors according to their sporadic or inherited Lynch syndrome (LS) origins. Since MSI-H tumors display an increased immunogenicity compared with MSS tumors, some authors have investigated differences in immune cell populations between sporadic and LS MSI-H endometrial cancer, showing that these two groups are distinct immunological entities with different types of immune cells in stroma and tumor, respectively $[65,66]$. In conclusion, given the evident benefit found in MSI-H/MMRd cancer patients treated with immune checkpoint inhibitors, all EC patients should be tested to define the MMR status at the time of diagnosis, including the immune-infiltrate and the expression of PD-1 and PD-L1, in order to establish their future eligibility for immunotherapy treatment $[67,68]$. Indeed, as the future of cancer treatment will rely on combination therapy strategies, several ongoing studies are evaluating the efficacy of immune checkpoint inhibitors associated with other immunotherapeutic agents, chemotherapy, radiotherapy, and targeted therapies in endometrial cancer. Interestingly, clinical evidence has suggested a strong correlation between PARP inhibition and PD-1/PD-L1 upregulation in different types of cancer. Therefore, the combined use of PARP inhibitors and anti-PD-L1 agents could show synergistic effects [69]. Further research is warranted to find new combination therapy strategies and to discover new specific biomarkers that can accurately predict the response to immunotherapy.

Author Contributions: Conceptualization-L.M.; methodology-L.M.; data acquisition and interpretation-L.M., S.M.B., G.C. and G.S.; discussion of the findings-L.M., G.C. and F.T.; writing original draft preparation-L.M. and G.C.; review and final editing-M.F., G.P., F.T., I.P., L.M., S.P. and P.B.P.; project administration and supervision-V.D.D. All authors have read and agreed to the published version of the manuscript.

Funding: This research received no external funding.

Conflicts of Interest: The authors declare no conflict of interest. 


\section{References}

1. Bray, F.; Ferlay, J.; Soerjomataram, I.; Siegel, R.L.; Torre, L.A.; Jemal, A. Global cancer statistics 2018: GLOBOCAN estimates of incidence and mortality worldwide for 36 cancers in 185 countries. CA Cancer J. Clin. 2018, 68, 394-424. [CrossRef] [PubMed]

2. American Cancer Society. Available online: https://www.cancer.org/cancer/endometrial-cancer/about/keystatistics.html (accessed on 20 February 2020).

3. Colombo, N.; Creutzberg, C.; Amant, F.; Bosse, T.; González-Martín, A.; Ledermann, J.; Marth, C.; Nout, R.; Querleu, D.; Mirza, M.; et al. ESMO-ESGO-ESTRO Consensus Conference on Endometrial Cancer: Diagnosis, treatment and follow-up. Ann. Oncol. 2017, 27, 16-41. [CrossRef] [PubMed]

4. National Cancer Institute. Endometrial cancer treatment Physician Data Query (PDQ). 2019. Available online: http://www.cancer.gov/cancertopics/pdq/treatment/endometrial/healthprofessional (accessed on 20 February 2020).

5. NCCN Clinical Practice Guidelines in Oncology. Available online: https://www.nccn.org/professionals/ physician_gls/pdf/uterine.pdf (accessed on 20 February 2020).

6. Ventriglia, J.; Paciolla, I.; Pisano, C.; Cecere, C.S.; Di Napoli, M.; Tambaro, R.; Califano, D.; Losito, S.; Scognamiglio, G.; Setola, S.V.; et al. Immunotherapy in ovarian, endometrial and cervical cancer: State of the art and future perspectives. Cancer Treat. Rev. 2017, 108, 17414-17419. [CrossRef] [PubMed]

7. Kratky, W.; Reis e Sousa, C.; Oxenius, A.; Spörri, R. Direct activation of antigen-presenting cells is required for CD8+ T-cell priming and tumor vaccination. Proc. Natl. Acad. Sci. USA 2011, 108, 17414-17419. [CrossRef] [PubMed]

8. Roche, P.A.; Cresswell, P. Antigen Processing and Presentation Mechanisms in Myeloid Cells. Microbiol. Spectr. 2016, 4. [CrossRef]

9. Sharpe, A.H. Mechanisms of costimulation. Immunol. Rev. 2016, 229, 5-11. [CrossRef]

10. Intlekofer, A.M.; Thompson, C.B. At the bench: Preclinical rationale for CTLA-4 and PD-1 blockade as cancer immunotherapy. J. Leukoc. Biol. 2013, 94, 25-39. [CrossRef]

11. Gasparri, M.L.; Attar, R.; Palaia, I.; Perniola, G.; Marchetti, C.; Di Donato, V.; Farooqui, A.A.; Papadia, A.; Benedetti Panici, P. Tumor infiltrating lymphocytes in ovarian cancer. Asian Pac. J. Cancer Prev. 2015, 16, 3635-3638. [CrossRef]

12. Vanderstraeten, A.; Tuyaerts, S.; Amant, F. The immune system in the normal endometrium and implications for endometrial cancer development. J. Reprod. Immunol. 2015, 109, 7-16. [CrossRef]

13. Chen, L.; Flies, D.B. Molecular mechanisms of T cell costimulation and co-inhibition. Nat. Rev. Immunol. 2013, 13, 227-242. [CrossRef]

14. Di Tucci, C.; Capone, C.; Galati, G.; Iacobelli, V.; Schiavi, M.C.; Di Donato, V.; Muzii, L.; Benedetti Panici, P. Immunotherapy in endometrial cancer: New scenarios on the horizon. J. Gynecol Oncol. 2019, 30 , e46. [CrossRef] [PubMed]

15. Pardoll, D.M. The blockade of immune checkpoints in cancer immunotherapy. Nat. Rev. Cancer 2012, 12, 252-264. [CrossRef]

16. Wu, Y.; Chen, W.; Xu, Z.P.; Gu, W. PD-L1 Distribution and Perspective for Cancer Immunotherapy-Blockade, Knockdown, or Inhibition. Front. Immunol. 2019, 497, 67-73. [CrossRef] [PubMed]

17. Alsaab, H.O.; Sau, S.; Alzhrani, R.; Tatiparti, K.; Bhise, K.; Kashaw, S.K.; Iyer, A.K. PD-1 and PD-L1 Checkpoint Signaling Inhibition for Cancer Immunotherapy: Mechanism, Combinations, and Clinical Outcome. Front. Pharmacol. 2017, 8, 561. [CrossRef]

18. Bokhman, J.V. Two pathogenetic types of endometrial carcinoma. Gynecol. Oncol. 1983, 15, 10-17. [CrossRef]

19. Lax, S.F. Molecular genetic pathways in various types of endometrial carcinoma: From a phenotypical to a molecular based classification. Virchows. Arch. 2004, 444, 213-223. [CrossRef]

20. Wilczyński, M.; Danielska, J.; Wilczyński, J. An update of the classical Bokhman's dualistic model of endometrial cancer. Prz. Menopauzalny. 2016, 15, 63-68. [CrossRef]

21. Kandoth, C.; Schultz, N.; Cherniack, A.D.; Akbani, R.; Liu, Y.; Shen, H.; Robertson, A.G.; Pashtan, I.; Shen, R.; Benz, C.C.; et al. Integrated genomic characterization of endometrial carcinoma. Nature 2013, 497, 67-73. [PubMed] 
22. McConechy, M.K.; Talhouk, A.; Leung, S.; Chiu, D.; Yang, W.; Senz, J.; Reha-Krantz, L.J.; Lee, C.-H.; Huntsman, D.G.; Gilks, C.B.; et al. Endometrial carcinomas with POLE exonuclease domain mutations have a favorable prognosis. Clin. Cancer Res. 2016, 22, 2865-2873. [CrossRef]

23. Billingsley, C.C.; Cohn, D.E.; Mutch, D.G.; Hade, E.M.; Goodfellow, P.J. Prognostic significance of POLE exonuclease domain mutations in high-grade endometrioid endometrial cancer on survival and recurrence. Int. J. Gynecol. Cancer 2016, 26, 933-938. [CrossRef]

24. Meng, B.; Hoang, L.N.; McIntyre, J.B.; Duggan, M.A.; Nelson, G.S.; Lee, C.H.; Köbel, M. POLE exonuclease domain mutation predicts long progression-free survival in grade 3 endometrioid carcinoma of the endometrium. Gynecol. Oncol. 2014, 134, 15-19. [CrossRef] [PubMed]

25. Ribic, C.M.; Sargent, D.J.; Moore, M.J.; Thibodeau, S.N.; French, A.J.; Goldberg, R.M.; Hamilton, S.R.; Laurent-Puig, P.; Gryfe, R.; Shepherd, L.E.; et al. Tumor microsatellite-instability status as a predictor of benefit from fluorouracil-based adjuvant chemotherapy for colon cancer. N. Engl. J. Med. 2003, 349, $247-257$. [CrossRef] [PubMed]

26. Popat, S.; Hubner, R.; Houlston, R.S. Systematic review of microsatellite instability and colorectal cancer prognosis. J. Clin. Oncol. 2005, 23, 609-618. [CrossRef]

27. Puzzoni, M.; Silvestris, N.; Leone, F.; Giampieri, R.; Faloppi, L.; Demurtas, L.; Dell'Aquila, E.; Marino, D.; Brunetti, O.; Garattini, S.K.; et al. The Immune Revolution in Gastrointestinal Tumours: Leading the Way or Just Following? Targ. Oncol. 2016, 11, 593-603. [CrossRef] [PubMed]

28. Mittica, G.; Ghisoni, E.; Giannone, G.; Aglietta, M.; Genta, S.; Valabrega, G. Checkpoint inhibitors in endometrial cancer: Preclinical rationale and clinical activity. Oncotarget 2017, 8, 90532-90544. [CrossRef]

29. Murali, R.; Soslow, R.A.; Weigelt, B. Classification of endometrial carcinoma: More than two types. Lancet Oncol. 2014, 15, e268-e278. [CrossRef]

30. Howitt, B.E.; Shukla, S.A.; Sholl, L.M.; Ritterhouse, L.L.; Watkins, J.C.; Rodig, S.; Stover, E.; Strickland, K.C.; D'Andrea, A.D.; Wu, C.J.; et al. Association of Polymerase e-Mutated and Microsatellite-Instable Endometrial Cancers with Neoantigen Load, Number of Tumor-Infiltrating Lymphocytes, and Expression of PD-1 and PD-L1. JAMA Oncol. 2015, 1, 1319-1323. [CrossRef]

31. Bellone, S.; Centritto, F.; Black, J.; Schwab, C.; English, D.; Cocco, E.; Lopez, S.; Bonazzoli, E.; Predolini, F.; Ferrari, F; et al. Polymerase $\varepsilon$ (POLE) ultra-mutated tumors induce robust tumor-specific CD4+ T cell responses in endometrial cancer patients. Gynecol. Oncol. 2015, 138, 11-17. [CrossRef]

32. Di Donato, V.; Iacobelli, V.; Schiavi, M.C.; Colagiovanni, V.; Pecorella, I.; Palaia, I.; Perniola, G.; Marchetti, C.; Musella, A.; Tomao, F.; et al. Impact of Hormone Receptor Status and Ki-67 Expression on Disease-Free Survival in Patients Affected by High-risk Endometrial Cancer. Int. J. Gynecol Cancer 2018, 28, 505-513. [CrossRef]

33. Gatalica, Z.; Vranic, S.; Xiu, J.; Swensen, J.; Reddy, S. High microsatellite instability (MSI-H) colorectal carcinoma: A brief review of predictive biomarkers in the era of personalized medicine. Fam. Cancer 2016, 15, 405-412. [CrossRef]

34. Inaguma, S.; Lasota, J.; Wang, Z.; Felisiak-Golabek, A.; Ikeda, H.; Miettinen, M. Clinicopathologic profile, immunophenotype, and genotype of CD274 (PD-L1)-positive colorectal carcinomas. Mod. Pathol. 2017, 30, 278-285. [CrossRef] [PubMed]

35. Nelson, B.H.; McAlpine, J.N. The more tumors change, the more they stay tame: Do T cells keep POLE ultramutated endometrial carcinomas in check? Gynecol. Oncol. 2015, 138, 1-2. [CrossRef]

36. Goodman, A.M.; Kato, S.; Bazhenova, L.; Patel, S.P.; Frampton, G.M.; Miller, V.; Stephens, P.J.; Daniels, G.A.; Kurzrock, R. Tumor Mutational Burden as an Independent Predictor of Response to Immunotherapy in Diverse Cancers. Mol. Cancer Ther. 2017, 16, 2598-2608. [CrossRef] [PubMed]

37. Yamashita, H.; Nakayama, K.; Ishikawa, M.; Nakamura, K.; Ishibashi, T.; Sanuki, K.; Ono, R.; Sasamori, H.; Minamoto, T.; Iida, K.; et al. Microsatellite instability is a biomarker for immune checkpoint inhibitors in endometrial cancer. Oncotarget 2018, 9, 5652-5664. [CrossRef] [PubMed]

38. Le, D.T.; Uram, J.N.; Wang, H.; Bartlett, B.R.; Kemberling, H.; Eyring, A.D.; Skora, A.D.; Luber, B.S.; Azad, N.S.; Laheru, D.; et al. PD-1 Blockade in Tumors with Mismatch-Repair Deficiency. N. Engl. J. Med. 2015, 372, 2509-2520. [CrossRef] [PubMed]

39. Mehnert, J.M.; Panda, A.; Zhong, H.; Hirshfield, K.; Damare, S.; Lane, K.; Sokol, L.; Stein, M.N.; Rodriguez-Rodriquez, L.; Kaufman, H.L. Immune activation and response to pembrolizumab in POLE-mutant endometrial cancer. J. Clin. Investig. 2016, 126, 2334-2340. [CrossRef] 
40. Ott, P.A.; Bang, Y.J.; Berton-Rigaud, D.; Elez, E.; Pishvaian, M.J.; Rugo, H.S.; Puzanov, I.; Mehnert, J.M.; Aung, K.L.; Lopez, J.; et al. Safety and Antitumor Activity of Pembrolizumab in Advanced Programmed Death Ligand 1-Positive Endometrial Cancer: Results From the KEYNOTE-028 Study. J. Clin. Oncol. 2017, 35, 2535-2541. [CrossRef]

41. Makker, V.; Rasco, D.; Vogelzang, N.J.; Brose, M.S.; Cohn, A.L.; Mier, J.; Di Simone, C.; Hyman, D.M.; Stepan, D.E.; Dutcus, C.E.; et al. Lenvatinib plus pembrolizumab in patients with advanced endometrial cancer: An interim analysis of a multicentre, open-label, single-arm, phase 2 trial. Lancet Oncol. 2019, 20,711-718. [CrossRef]

42. Marabelle, A.; Le, D.T.; Ascierto, P.A.; Di Giacomo, A.M.; De Jesus-Acosta, A.; Delord, J.P.; Geva, R.; Gottfried, M.; Penel, N.; Hansen, A.R. Efficacy of Pembrolizumab in Patients with Noncolorectal High Microsatellite Instability/Mismatch Repair-Deficient Cancer: Results from the Phase II KEYNOTE-158 Study. J. Clin. Oncol. 2020, 38, 1-10. [CrossRef]

43. Santin, A.D.; Bellone, S.; Buza, N.; Choi, J.; Schwartz, P.E.; Schlessinger, J.; Lifton, R.P. Regression of Chemotherapy-Resistant Polymerase $\varepsilon$ (POLE) Ultra-Mutated and MSH6 Hyper-Mutated Endometrial Tumors with Nivolumab. Clin. Cancer Res. 2016, 22, 5682-5687. [CrossRef]

44. Oaknin ADuska, L.R.; Sullivan, R.J.; Pothuri, B.; Ellard, S.L.; Leath, C.A., III; Moreno, V.; Kristeleit, R.S.; Guo, W.; Danaee, H. Preliminary safety, efficacy, and pharmacokinetic/pharmacodynamic characterization from GARNET, a phase I/II clinical trial of the anti-PD-1 monoclonal antibody, TSR-042, in patients with recurrent or advanced MSI-h and MSS endometrial cancer. Gynecol. Oncol. 2019, 154, 17. [CrossRef]

45. Fleming, G.F.; Emens, L.A.; Eder, J.P.; Hamilton, E.P.; Liu, J.F.; Liu, B.; Molinero, L.; Fasso, M.; O’Hear, C.; Braiteh, F.S. Clinical activity, sefety and biomarker results from a phase Ia study of atezolizumab (atezo)in advanced/recurrent endometrial cancer(rEC). J. Clin. Oncol. 2017, 35, 5585. [CrossRef]

46. Konstantinopoulos, P.A.; Luo, W.; Liu, J.F.; Gulhan, D.C.; Krasner, C.; Ishizuka, J.J.; Gockley, A.A.; Buss, M.; Growdon, W.B.; Crowe, H. Phase II Study of Avelumab in Patients with Mismatch Repair Deficient and Mismatch Repair Proficient Recurrent/Persistent Endometrial Cancer. J. Clin. Oncol. 2019, 37, 2786-2794. [CrossRef] [PubMed]

47. Antill, Y.C.; Kok, P.S.; Robledo, K.; Barnes, E.; Friedlander, M.; Baron-Hay, S.E.; Shannon, C.M.; Coward, J.; Beale, P.J.; Goss, G.; et al. Activity of durvalumab in advanced endometrial cancer (AEC) according to mismatch repair (MMR) status: The phase II PHAEDRA trial (ANZGOG1601). Presented at ASCO 2019. J. Clin. Oncol. 2019, 37, 5501. [CrossRef]

48. Clinicaltrial.gov. Available online: https://clinicaltrials.gov/ct2/show/NCT03572478 (accessed on 20 February 2020).

49. Clinicaltrial.gov. Available online: https://clinicaltrials.gov/ct2/show/NCT02982486 (accessed on 20 February 2020).

50. Clinicaltrial.gov. Available online: https://clinicaltrials.gov/ct2/show/NCT03241745 (accessed on 20 February 2020).

51. Clinicaltrial.gov. Available online: https://clinicaltrials.gov/ct2/show/NCT02549209 (accessed on 20 February 2020).

52. Clinicaltrial.gov. Available online: https://linicaltrials.gov/ct2/show/NCT03276013 (accessed on 20 February 2020).

53. Clinicaltrial.gov. Available online: https://clinicaltrials.gov/ct2/show/NCT03517449 (accessed on 20 February 2020).

54. Clinicaltrial.gov. Available online: https://clinicaltrials.gov/ct2/show/NCT03914612 (accessed on 20 February 2020).

55. Clinicaltrial.gov. Available online: https://clinicaltrials.gov/ct2/show/NCT03884101 (accessed on 20 February 2020).

56. Clinicaltrial.gov. Available online: https:/clinicaltrials.gov/ct2/show/NCT03503786 (accessed on 20 February 2020).

57. Clinicaltrial.gov. Available online: https:/clinicaltrials.gov/ct2/show/NCT04269200 (accessed on 20 February 2020).

58. Clinicaltrial.gov. Available online: https://clinicaltrials.gov/ct2/show/NCT03694262 (accessed on 20 February 2020). 
59. Buchbinder, E.I.; Desai, A. CTLA-4 and PD-1 Pathways: Similarities, Differences, and Implications of Their Inhibition. Am. J. Clin. Oncol. 2016, 39, 98-106. [CrossRef]

60. De Felice, F.; Marchetti, C.; Palaia, I.; Musio, D.; Muzii, L.; Tombolini, V.; Benedetti Panici, P. Immunotherapy of ovarian cancer: The role of checkpoint inhibitors. J. Immunol. Res. 2015, 2015, 191832. [CrossRef]

61. Michot, J.M.; Bigenwald, C.; Champiat, S.; Collins, M.; Carbonnel, F.; Postel-Vinay, S.; Berdelou, A.; Varga, A.; Bahleda, R.; Hollebecque, A.; et al. Immune-related adverse events with immune checkpoint blockade: A comprehensive review. Eur. J. Cancer 2016, 378, 158-168. [CrossRef]

62. Postow, M.A.; Sidlow, R.; Hellman, M.D. Immune-related adverse events associated with immune checkpoint blockade. N. Engl. J. Med. 2018, 378, 158-168. [CrossRef]

63. Weber, J.S.; Hodi, F.S.; Wolchok, J.D.; Topalian, S.L.; Schadendorf, D.; Larkin, J.; Sznol, M.; Long, G.V.; Li, H.; Waxman, I.M.; et al. Safety profile of nivolumab monotherapy: A pooled analysis of patients with advanced melanoma. J. Clin. Oncol. 2017, 35, 785-792. [CrossRef]

64. Taube, J.M.; Klein, A.; Brahmer, J.R.; Xu, H.; Pan, X.; Kim, J.H.; Chen, L.; Pardoll, D.M.; Topalian, S.L.; Anders, R.A. Association of PD-1, PD-1 ligands, and other features of the tumor immune microenvironment with response to anti-PD-1 therapy. Clin. Cancer Res. 2014, 20, 5064-5074. [CrossRef]

65. Immune Microenvironment in Microsatellite-Instable Endometrial Cancers: Hereditary or Sporadic Origin Matters. Clin. Cancer Res. 2017, 23, 4473-4481. [CrossRef] [PubMed]

66. Ramchander, N.C.; Ryan, N.A.J.; Walker, T.D.J.; Harries, L.; Bolton, J.; Bosse, T.; Evans, D.G.; Crosbie, E.J. Distinct Immunological Landscapes Characterize Inherited and Sporadic Mismatch Repair Deficient Endometrial Cancer. Front. Immunol. 2019, 21, 2167-2180. [CrossRef] [PubMed]

67. Ryan, N.A.J.; Glaire, M.A.; Blake, D.; Cabrera-Dandy, M.; Evans, D.G.; Crosbie, E.J. The proportion of endometrial cancers associated with Lynch syndrome: A systematic review of the literature and meta-analysis. Genet. Med. 2019, 21, 2167-2180. [CrossRef] [PubMed]

68. Crosbie, E.J.; Ryan, N.A.; Arends, M.J.; Bosse, T.; Burn, J.; Cornes, J.M.; Crawford, R.; Eccles, D.; Frayling, I.M.; Ghaem-Maghami, S.; et al. The Manchester International Consensus Group recommendations for the management of gynecological cancers in Lynch syndrome. Genet. Med. 2019, 21, 2390-2400. [CrossRef]

69. Jiao, S.; Xia, W.; Yamaguchi, H.; Wei, Y.; Chen, M.K.; Hsu, J.M.; Hsu, J.L.; Yu, W.H.; Du, Y.; Lee, H.H.; et al. PARP Inhibitor Upregulates PD-L1 Expression and Enhances Cancer-Associated Immunosuppression. Clin. Cancer Res. 2017, 23, 3711-3720. [CrossRef] 